\title{
Legionella drozanskii sp. nov., Legionella rowbothamii sp. nov. and Legionella fallonii sp. nov.: three unusual new Legionella species
}

\author{
1 Division of Life Sciences, \\ King's College London, \\ Franklin-Wilkins Building, \\ 150 Stamford Street, \\ London SE1 8WA, UK \\ 2 Division of Bacterial and \\ Mycotic Diseases, Centers \\ for Disease Control and \\ Prevention (CDC), Atlanta, \\ GA 30333, USA \\ 3 Infectious Diseases \\ Laboratories, Institute of \\ Medical and Veterinary \\ Science, Frome Road, \\ Adelaide, SA, 5000, \\ Australia \\ 4 PHLS Central Public Health \\ Laboratory, Colindale, \\ London NW9 5HT, UK \\ 5 Department of \\ Microbiology, University of \\ Bristol, Bristol BS8 1TD, UK \\ 6 WHO Collaborative Center \\ for Rickettsial Reference \\ and Research, Faculté de \\ Medecine-27, Boulevard \\ Jean Moulin, Marseille, \\ Cedex 5, France
}

\author{
Adenike A. Adeleke, ${ }^{1}$ Barry S. Fields, ${ }^{2}$ Robert F. Benson, ${ }^{2}$ \\ Maryam I. Daneshvar, ${ }^{2}$ Janet M. Pruckler, ${ }^{2}$ Rodney M. Ratcliff, ${ }^{3}$ \\ Timothy G. Harrison, ${ }^{4}$ Robbin S. Weyant, ${ }^{2}$ Richard J. Birtles, ${ }^{5}$ \\ Didier Raoult ${ }^{6}$ and Mahmoud A. Halablab1
}

Author for correspondence: Mahmoud A. Halablab. Tel: +44207848 4281. Fax: +442078484500. e-mail: mahmoud.halablab@kcl.ac.uk
Keywords: amoeba, autofluorescence, branched-chain fatty acids, mip, DNA hybridization

\section{INTRODUCTION}

Members of the genus Legionella are the established aetiological agents of Legionnaires' disease and its milder relative, Pontiac fever. Legionellae have been described as obligate parasites of single-celled protozoa (Rowbotham, 1986; Fields, 1996). Similarly, Legionella-like amoebal pathogens (LLAPs) are primarily obligate intracellular parasites of amoebae

Abbreviations: BCYE, buffered charcoal yeast extract $\alpha$; CFA, cellular fatty acid; LLAP, Legionella-like amoebal pathogen; SAT, slide agglutination test.

The GenBank accession numbers for approximately 600 bases of sequence of the mip gene of Legionella lytica and strains LLAP-1 ${ }^{\top}$, LLAP-6 ${ }^{\top}$, LLAP-7, LLAP-9, LLAP-10 ${ }^{\top}$ and 4313-GER-E are AF148982, AF148983, AF148984, AF148985, AF148986, AF148987 and AF148988, respectively.
(Adeleke et al., 1996). These bacteria derived their name from their ability to infect and multiply in amoebae in an identical way to members of the genus Legionella (Rowbotham, 1986; Fields et al., 1990). LLAP-3 was isolated from the sputum of a pneumonia patient, following co-culture of the sputum with amoebae. All the other LLAP strains (except Legionella lytica) were originally isolated from sites sampled during investigations into individual cases or clusters of cases of Legionnaires' disease. There is also serological evidence associating LLAPs with respiratory disease in humans (Rowbotham, 1993; Benson et al., 1995).

The grouping together of members of the genus Legionella is based on phenotypic similarities and is supported by molecular techniques (Brenner et al., 
A. A. Adeleke and others

Table 1. Bacterial strains

NYA, Not yet accessioned.

\begin{tabular}{|c|c|c|c|}
\hline Legionella species/serogroup & Serogroup & ATCC no. & Original designation \\
\hline \multirow[t]{15}{*}{ L. pneumophila } & Sgp1 & 33152 & Philadelphia $1^{\mathrm{T}}$ \\
\hline & Sgp2 & 33154 & Togus 1 \\
\hline & Sgp3 & 33155 & Bloomington 2 \\
\hline & Sgp4 & 33156 & Los Angeles \\
\hline & Sgp5 & 33216 & Dallas 1 \\
\hline & Sgp6 & 33215 & Chicago 2 \\
\hline & Sgp7 & 33823 & Chicago 8 \\
\hline & Sgp8 & 35096 & Concord 3 \\
\hline & Sgp9 & 35289 & IN-23-G1-C2 \\
\hline & Sgp10 & 43283 & Leiden 1 \\
\hline & Sgp11 & 43130 & 797-PA-H \\
\hline & Sgp12 & 43290 & $570-\mathrm{CO}-\mathrm{H}$ \\
\hline & Sgp13 & 43736 & $82 \mathrm{~A} 3105$ \\
\hline & Sgp14 & 43703 & 1169-MN-H \\
\hline & Sgp15 & 35251 & Lansing 3 \\
\hline L. adelaidensis & & 49625 & 1762-AUS-E ${ }^{\mathrm{T}}$ \\
\hline L. anisa & & 35292 & WA-316-C3 $3^{\mathrm{T}}$ \\
\hline L. birminghamensis & & 43702 & 1407-AL-H ${ }^{\mathrm{T}}$ \\
\hline \multirow[t]{2}{*}{ L. bozemanii } & Sgp1 & 33217 & $\mathrm{WIGA}^{\mathrm{T}}$ \\
\hline & $\operatorname{Sgp} 2$ & 35545 & Toronto 3 \\
\hline L. brunensis & & 43878 & $444-1^{\mathrm{T}}$ \\
\hline L. cherrii & & 35252 & $\mathrm{ORW}^{\mathrm{T}}$ \\
\hline L. cincinnatiensis & & 43753 & $72-\mathrm{OH}-\mathrm{H}^{\mathrm{T}}$ \\
\hline L. dumoffii & & 33279 & $N Y-23^{T}$ \\
\hline L. erythra & & 35303 & SE-32-A-C $8^{T}$ \\
\hline L. fairfieldensis & & 49588 & 1725-AUS-E ${ }^{T}$ \\
\hline \multirow[t]{2}{*}{ L. feeleii } & Sgp1 & 35072 & WO- $44 C^{\mathrm{T}}$ \\
\hline & Sgp2 & 35849 & 691-WI-H \\
\hline L. geestiana & & 49504 & $1308^{\mathrm{T}}$ \\
\hline L. gormanii & & 33297 & LS $-13^{\mathrm{T}}$ \\
\hline L. gratiana & & 49413 & Lyon $8420412^{\mathrm{T}}$ \\
\hline \multirow[t]{2}{*}{ L. hackeliae } & Sgp1 & 35250 & Lansing $2^{\mathrm{T}}$ \\
\hline & Sgp2 & 35999 & 798-PA-H \\
\hline L. israelensis & & 43119 & Bercovier $4^{\mathrm{T}}$ \\
\hline L. jamestowniensis & & 35298 & JA-26-G1-E2 ${ }^{\mathrm{T}}$ \\
\hline L. jordanis & & 33623 & BL-540 \\
\hline L. lansingensis & & 49751 & 1677-MI-H \\
\hline L. londoniensis & & 49505 & $1477^{\mathrm{T}}$ \\
\hline \multirow{2}{*}{ L. longbeachae } & Sgp1 & 33462 & Long Beach $4^{\mathrm{T}}$ \\
\hline & Sgp2 & 33484 & Tucker 1 \\
\hline L. lytica & & NYA & $\mathrm{L} 2^{\mathrm{T}}$ \\
\hline L. maceachernii & & 35300 & $P X-1-G 2-E 2^{T}$ \\
\hline L. micdadei & & 33218 & TATLOCK $^{\mathrm{T}}$ \\
\hline L. moravica & & 43877 & $316-36^{\mathrm{T}}$ \\
\hline L. nautarum & & 49506 & $1224^{\mathrm{T}}$ \\
\hline L. oakridgensis & & 33761 & Oak Ridge $10^{\mathrm{T}}$ \\
\hline L. parisiensis & & 35299 & PF-209C-C2 $2^{T}$ \\
\hline L. quateriensis & & 49507 & $1335^{\mathrm{T}}$ \\
\hline \multirow{2}{*}{ L. quinlivanii } & Sgp1 & 43830 & 1442-AUS-E ${ }^{T}$ \\
\hline & Sgp2 & NYA & $\mathrm{LC} 870$ \\
\hline L. rubrilucens & & 35304 & WA-270-C2 ${ }^{\mathrm{T}}$ \\
\hline \multirow[t]{2}{*}{ L. sainthelensi } & Sgp1 & 35248 & Mt St Helens ${ }^{T}$ \\
\hline & Sgp2 & 49322 & 1489-CA-H \\
\hline
\end{tabular}


Table 1 (cont.)

\begin{tabular}{|lcll|}
\hline Legionella species/serogroup & Serogroup & ATCC no. & Original designation \\
\hline L. santicrucis & & 35301 & SC-63-C7 \\
L. shakespearei & & 49655 & $214^{\mathrm{T}}$ \\
L. spiritensis & Sgp1 & 35249 & Mt St Helens $9^{\mathrm{T}}$ \\
L. steigerwaltii & & 35302 & SC-18-C9 \\
L. tucsonensis & & 49180 & $1087-\mathrm{AZ}^{\mathrm{T}}-\mathrm{H}^{\mathrm{T}}$ \\
L. wadsworthii & 33877 & $81-716 \mathrm{~A}^{\mathrm{T}}$ \\
L. waltersii & 51914 & $2074-\mathrm{AUS}-\mathrm{E}^{\mathrm{T}}$ \\
L. worsleiensis & 49508 & $1347^{\mathrm{T}}$ \\
Legionella genomospecies 1 & & 51913 & $2055-$ AUS-E \\
\hline
\end{tabular}

1985; Brenner, 1986; Fry et al., 1991; Harrison \& Saunders, 1994; Hookey, 1995; Benson et al., 1996; Hookey et al., 1996; Ratcliff et al., 1997, 1998). There are few discriminatory phenotypic tests for the differentiation of Legionella species (Benson \& Fields, 1998; Harrison \& Saunders, 1994). Hence, definitive speciation relies on a variety of methods, the most conclusive of which are DNA homology studies (Brenner, 1986; Fox et al., 1992; Harrison \& Saunders, 1994; Benson et al., 1996). Recently, rapid identification of legionellae has been significantly enhanced with the development of a genotyping scheme based on the mip gene (Ratcliff et al., 1998).

Unlike legionellae, LLAPs exhibit little or no growth on bacteriological media and the cultivation of these bacteria on laboratory media cannot be considered routine. Consequently, the characterization and classification of this interesting group of bacteria has been limited. The only LLAP strain that has been validly named was classified in the absence of DNA homology data (Drozanski, 1991; Hookey et al., 1996). This strain was initially classified in a separate genus as Sarcobium lyticum, based on the phenotypic features of the organism and its obligate intracellular existence or pathogenicity for amoebae (Drozanski, 1991). However, S. lyticum was subsequently transferred to the genus Legionella as L. lytica, on the basis of $16 \mathrm{~S}$ rRNA sequence analysis (Hookey et al., 1996).

The current study was conducted to determine the taxonomic identity of LLAPs. The study adopted a polyphasic approach involving the use of phylogenetic relationships, cultural and staining characteristics, biochemical and serological reactions, as well as chemotaxonomic analyses, including the analysis of cell wall components and total DNA relatedness (Murray et al., 1990; Priest \& Austin, 1993).

\section{METHODS}

Strains. L. lytica was provided by Professor W. Drozanski of Maria-Curie-Sklodowska University, Lublin, Poland, while LLAP- ${ }^{\mathrm{T}}$, LLAP-6 ${ }^{\mathrm{T}}$, LLAP-7, LLAP-9 and LLAP-10 ${ }^{\mathrm{T}}$ were supplied by Dr T. J. Rowbotham of the Public Health Laboratory, Leeds, UK. A previously unidentified Legionella-like strain, 4313-GER-E, a drinking water iso- late, was supplied by Dr Rolf Michel of the ErnstRodenwaldt-Institut, Koblenz, Germany, to CDC for identification.

Type and reference strains representing 40 species, 1 genomospecies and 63 serogroups of Legionella were used (Table 1). In addition, 15 unnamed Legionella-like organisms (1-15) were also studied.

Isolation. L. lytica was isolated as a bacterial infection of Acanthamoeba. The strain was found in a culture of a small free-living amoeba isolated from Polish soil in 1954 (Drozanski, 1956; Schlecht \& Drozanski, 1987). LLAP-1 ${ }^{\mathrm{T}}$, LLAP-6 ${ }^{\mathrm{T}}$, LLAP-7, LLAP-9 and LLAP-10 ${ }^{\mathrm{T}}$ were isolated via amoebal enrichment from various sources in the UK. The strains were isolated between 1981 and 1994 following co-culture of respective samples with amoebae as described by Rowbotham $(1983,1993)$. The sources of the samples included a tank of potable well water, liquefier tower, whirlpool spa, factory cooling water and a ship airconditioning system. In some instances, known Legionella species were isolated from the same sources. Although each of these sources was associated with confirmed cases of Legionnaires' disease, there were instances when no legionellae were isolated by conventional techniques. For example, LLAP-7 was isolated from a tidemark sample of a whirlpool spa bath in a hotel in Leicestershire, UK in 1991. The spa was associated with two cases of Legionnaires' disease where the patients had serological evidence of infection with Legionella pneumophila serogroup 1. L. pneumophila serogroup 1 was detected by immunofluorescence in a smear of the tidemark sample while LLAP7 was isolated following co-culture of the same sample with Acanthamoeba palestinensis at $35^{\circ} \mathrm{C}$. L. pneumophila serogroup 1 was also isolated from the biofilm in the overflow channel after co-culture with $A$. palestinensis at $35^{\circ} \mathrm{C}$. However, no legionellae were isolated from either sample by conventional culture. A variety of protozoa, including flagellates, ciliates, amoebae, bacteria-infected amoebae and amoebal cysts, were seen in the original samples.

Co-culture of LLAP strains. All LLAP strains, including $L$. lytica were co-cultured with suitable host amoebae at 30 or $35^{\circ} \mathrm{C}$ (Adeleke, 1998). Co-culture samples containing accumulations of extracellular bacteria were inoculated onto buffered charcoal yeast extract $\alpha$ (BCYE; Edelstein, 1981) agar plates and incubated at $30^{\circ} \mathrm{C}$. Single colonies from each LLAP strain were subcultured on BCYE and grown at $30{ }^{\circ} \mathrm{C}$.

Growth and biochemical tests. LLAP strains, including $L$. lytica, were grown on BCYE at $30^{\circ} \mathrm{C}$ while all Legionella 
and the unnamed Legionella-like strains were grown on $\mathrm{BCYE}$ at $35^{\circ} \mathrm{C}$. Gram staining and determination of oxidase and catalase activities, L-cysteine requirement, colony autofluorescence and glucose utilization were carried out as described by Brenner et al. (1985).

Cellular fatty acids (CFAs) and isoprenoid quinones. Bacterial cells to be used for fatty acid and quinone analyses were grown on BCYE for $72-96 \mathrm{~h}$ at $30^{\circ} \mathrm{C}$. Cellular lipids were saponified and the liberated fatty acids were methylated and analysed by capillary GLC (Weyant et al., 1996) using a commercially available software package (MIDI, Newark, DE, USA). The amide-linked hydroxy acids that were not totally released by this saponification procedure were completely released by a subsequent acid hydrolysis of the methanolic aqueous layer after the methylation step (Weyant et al., 1996). The identification of fatty acids and determination of double bond positions in monounsaturated acids were accomplished by GLC and GLC-MS. The confirmation of hydroxy acids was accomplished by both acetylation and GLC-MS analysis as previously described (Weyant et al., 1996).

Isoprenoid quinones were extracted from $100 \mathrm{mg}$ lyophilized cells and were analysed by reverse-phase HPLC and MS (Moss \& Guerrant, 1983).

Serology. Formalin-killed antigen suspensions of LLAP strains were tested with rabbit antisera prepared against the type strains of 40 species and 1 genomospecies, and included 63 serogroups by the slide agglutination test (SAT) (Thacker et al., 1985; Benson et al., 1996).

16S rRNA sequence analysis. Genomic DNA was extracted from LLAP strains and amplified using PCR. The 16S rRNA gene sequences were then determined and analysed as described previously (Adeleke et al., 1996; Birtles et al., 1996).

Genotyping. Genotyping, utilizing the mip gene, was performed by gene amplification and dye terminator chemistry (Applied Biosystems) as described by Ratcliff et al. (1998). The sequences were analysed and a UPGMA dendrogram produced using the GeneCompar program (Applied Maths).

DNA hybridization. DNA from LLAP- $1^{\mathrm{T}}$, LLAP-6 ${ }^{\mathrm{T}}$, LLAP7FL, LLAP-7NF, LLAP-9, LLAP-10 $0^{\mathrm{T}}$ and L. lytica was extracted, purified, enzymically labelled and tested in reassociation experiments against one another, type strains of 36 validly named Legionella species, 14 unnamed species and the Legionella-like strain 4313-GER-E. Legionella anisa, Legionella rubrilucens, Legionella cherii, Legionella steigerwaltii, Legionella santicrucis and unnamed strain RI 227 were not included in the tests because each of them share at least $50 \%$ DNA relatedness with a Legionella species that was tested. DNA relatedness was determined by the hydroxyapatite method at $60{ }^{\circ} \mathrm{C}$. All experiments were performed at least twice. The methods for DNA extraction, purification and hybridization have been described by Brenner et al. (1978).

\section{RESULTS}

\section{Cultural characteristics}

All seven strains showed limited growth on BCYE and required cysteine for growth. No growth was observed on Trypticase soy agar and blood agar plates. All early grown colonies had a characteristic grey-blue colour and ground glass appearance. However, after pro- longed incubation, each strain developed its own distinctive morphology. LLAP- $6^{\mathrm{T}}$ colonies developed a bright yellow pigmentation. Colonies of strain 4313GER-E were found to have an identical appearance and colour to LLAP- $6^{\mathrm{T}}$. LLAP- $6^{\mathrm{T}}$, LLAP-9 and $L$. lytica exhibited blue-white autofluorescence on exposure to long wavelength UV light, while LLAP- $1^{\text {T }}$ and LLAP-10 ${ }^{\mathrm{T}}$ did not autofluoresce. When grown on BCYE, two colony types were observed in LLAP-7 cultures. One type showed blue-white autofluorescence while the other was non-fluorescent on exposure to long wavelength UV light. The strains were designated LLAP-7FL and LLAP-7NF, respectively. In natural light LLAP-7FL colonies had an olive to yellow colour. For all strains, cells were Gram-negative and catalase-positive. All strains were oxidase-negative, except for LLAP- $10^{\mathrm{T}}$ which had a weakly positive oxidase reaction. None of the strains produced acid from D-glucose.

\section{CFA and isoprenoid quinone content}

The CFA compositions of the strains tested are presented in Table 2 . All strains in the current study contained high concentrations $(>20 \%)$ of branchedchain fatty acids. The major or predominant branchedchain fatty acids included a-15:0, i-16:0 and a-17:0 with smaller amounts $(0-9 \%)$ of several other branched acids, including i-13:0, a-13:0, i-14:0, i15:0, i-16:1?, i-17:0, i-18:0, i-19:0 and a-19:0. Straight-chain and other acids detected included 12:0,

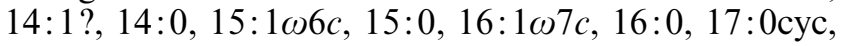
17:0, 18:0, 19:0 and 20:0. Small to moderate amounts (trace-11\%) of branched- or straight-chain, esterlinked hydroxy acids were detected in some strains. In the case of LLAP-6 ${ }^{\mathrm{T}}$, LLAP-9 and 4313-GER-E, these ester-linked hydroxy acids were useful for classification and differentiation.

Examination of the qualitative and quantitative fatty acid data showed that the strains tested could be placed into at least four major CFA groups (Table 2).

All the strains tested contained ubiquinones with 10 , $11,12,13$ and 14 isoprene units (Q-10, Q-11, Q-12, Q13 and Q-14, respectively) in the polyprenoid side chain and no menaquinones were detected. The major ubiquinones in all strains were Q-12 and Q-13, which were present at a concentration approximately four times the concentration of Q-10, Q-11 and Q-14.

\section{Serological reactions}

LLAP- ${ }^{\mathrm{T}}$ showed varying degrees of cross-reaction with other Legionella species and serogroups in SATs. LLAP- $6^{\mathrm{T}}$ showed strong $(4+)$ cross-reactions to both unabsorbed and absorbed Legionella bozemanii serogroup 2. Strong $(4+)$ reactions were also noted with unabsorbed antisera to L. bozemanii serogroup 1 and Legionella longbeachae serogroup 2. However, no reactions were observed with the corresponding absorbed antisera. There were notable $(4+)$ reactions to 
Table 2. CFA compositions of LLAP strains and strain 4313-GER-E

Values are the percentage of total fatty acids and are given as arithmetic ranges; T, trace $(0 \cdot 4-0 \cdot 8 \%)$. Numbers before colons refer to the number of carbon atoms; numbers after colons refer to the number of double bonds; $\mathrm{OH}$, hydroxy group at the $2(\alpha)$ or $3(\beta)$ position from the carboxyl end; i, methyl branch at the iso carbon atom; a, methyl branch at the anteiso carbon atom; $\omega$, double bond position from the hydrocarbon end of the carbon chain; c, cis isomer; cyc, cyclopropane ring structure; ?, position of the double bond is unknown.

\begin{tabular}{|c|c|c|c|c|c|c|c|c|}
\hline \multirow[t]{2}{*}{ Strain } & \multirow{2}{*}{$\begin{array}{l}\text { Group } 1 \\
\text { LLAP-1 }\end{array}$} & \multicolumn{4}{|c|}{ Group 2} & \multirow{2}{*}{$\begin{array}{l}\text { Group } 3 \\
\text { LLAP-9 }\end{array}$} & \multicolumn{2}{|c|}{ Group 4} \\
\hline & & LLAP-7FL & LLAP-7NF & LLAP-10 & L. lytica & & LLAP-6 & 4313-GER-E \\
\hline $3-\mathrm{OH}-10: 0$ & - & - & - & - & - & 2 & - & - \\
\hline $12: 0$ & - & - & $\mathrm{T}$ & - & - & 2 & - & - \\
\hline 3-OH-12:0 & - & - & - & - & - & 3 & - & - \\
\hline $1-13: 0$ & - & - & - & - & - & - & $2-3$ & $3-5$ \\
\hline$a-13: 0$ & $\mathrm{~T}-1$ & $0-2$ & $0 \cdot 9-1$ & - & $1-2$ & $1-2$ & $0-3$ & - \\
\hline $1-14: 0$ & $1-3$ & $6-9$ & $4-5$ & $4-5$ & $6-9$ & 2 & 5 & $4-5$ \\
\hline $14: 1 ?$ & $2-3$ & 1 & 1 & 1 & $1-2$ & $1-2$ & $1-2$ & $2-3$ \\
\hline $14: 0$ & $4-6$ & $0-1$ & 1 & $2-3$ & $2-3$ & $3-6$ & $2-3$ & $3-5$ \\
\hline $\mathrm{i}-15: 0$ & $\mathrm{~T}-1$ & - & $\mathrm{T}$ & $\mathrm{T}$ & - & - & 5 & $5-6$ \\
\hline$a-15: 0$ & $27-30$ & $25-42$ & $47-51$ & $12-15$ & $28-29$ & $9-14$ & $12-16$ & $15-17$ \\
\hline $15: 1 \omega 6 c$ & $5-7$ & $1-2$ & $0-1$ & $3-4$ & $1-2$ & 1 & $2-3$ & $2-3$ \\
\hline $15: 0$ & $2-3$ & - & $0-\mathrm{T}$ & $2-3$ & 2 & 1 & $1-2$ & $1-2$ \\
\hline 3-OH-14:0 & - & - & - & - & $0-\mathrm{T}$ & $2-11$ & $0-\mathrm{T}$ & $0-1$ \\
\hline $\mathrm{i}-16: 1 ?$ & $1-2$ & - & $0-\mathrm{T}$ & - & - & - & - & - \\
\hline i-16:0 & $9-10$ & $5-10$ & $5-7$ & $11-13$ & 4-6 & $1-2$ & $4-5$ & $2-5$ \\
\hline $16: 1 \omega 7 c$ & $18-20$ & $11-15$ & $13-14$ & $21-27$ & $10-14$ & $23-26$ & $16-22$ & $17-27$ \\
\hline $16: 0$ & $6-10$ & 4-8 & $5-10$ & $15-19$ & $10-14$ & $14-18$ & $9-10$ & $9-12$ \\
\hline $\mathrm{i}-3-\mathrm{OH}-15: 0$ & - & - & - & - & - & - & $2-4$ & $1-4$ \\
\hline 2-OH-15:0 & - & - & - & - & - & $\mathrm{T}-3$ & - & $0-1$ \\
\hline $\mathrm{i}-17: 0$ & - & - & - & - & - & - & $4-5$ & $2-5$ \\
\hline a-17:0 & $3-6$ & $5-11$ & $7-10$ & $2-3$ & $6-7$ & $2-4$ & $3-4$ & $2-4$ \\
\hline $17: 0$ сус & $2-6$ & $0-8$ & $2-10$ & $2-6$ & $8-10$ & $2-3$ & $5-8$ & $1-11$ \\
\hline $17: 0$ & - & $1-3$ & $\mathrm{~T}$ & 2 & 2 & $1-2$ & 3 & $1-2$ \\
\hline $\mathrm{i}-18: 0$ & - & $2-8$ & 1 & $\mathrm{~T}$ & $2-5$ & 1 & $2-6$ & $0-2$ \\
\hline $18: 0$ & - & $1-5$ & 1 & $6-7$ & $3-4$ & $6-10$ & 4 & $2-4$ \\
\hline $\mathrm{i}-19: 0$ & - & - & - & - & - & - & $0-1$ & $0-1$ \\
\hline $19: 0$ & - & - & - & $1-2$ & - & - & - & - \\
\hline$a-19: 0$ & - & $1-4$ & $\mathrm{~T}$ & $0-\mathrm{T}$ & $1-2$ & $1-2$ & $0-1$ & $0-1$ \\
\hline $20: 0$ & $1-4$ & - & - & $1-2$ & - & - & & \\
\hline
\end{tabular}

unabsorbed Legionella anisa serogroup 1, but the corresponding absorbed serum was unavailable. Cross-reactions between LLAP- $6^{\mathrm{T}}$ and antisera to $L$. bozemanii serogroup 2 and to $L$. anisa serogroup 1 were noted in SATs. Strain 4313-GER-E reacted strongly $(4+)$ with unabsorbed $L$. longbeachae serogroup 1 but not with the absorbed antiserum. LLAP7FL showed significant reactions $(3+)$ to both absorbed and unabsorbed L. longbeachae serogroup 1 . Like LLAP-7FL, LLAP-7NF showed strong $(4+)$ reactions to absorbed and unabsorbed L. longbeachae serogroup 1 in SATs. No further cross-reactions were noted between LLAP-7NF and other Legionella strains and serogroups. LLAP-9 showed considerable $(4+)$ reactions to antiserum to Legionella wadsworthii. $L$. lytica had significant $(3+/ 4+)$ reactions to $L$. bozemanii serogroup 2, L. longbeachae serogroups 1 and 2 and Legionella spiritensis serogroup 1. LLAP-
$10^{\mathrm{T}}$ reacted strongly $(4+)$ with both unabsorbed and absorbed sera to Legionella feeleii serogroup 2 in SATs.

\section{SrRNA sequence analysis}

The 16S rRNA sequence similarity over 1303 bases between the LLAP strains tested and those of previously described Legionella species was $93 \cdot 4-97 \cdot 0 \%$. The results of sequence analyses and GenBank accession numbers for the LLAP strains have been published previously (Adeleke et al., 1996; Birtles et al., 1996).

\section{Genotyping}

Approximately 600 bases of sequence of the mip gene was determined for each LLAP strain. The sequences 

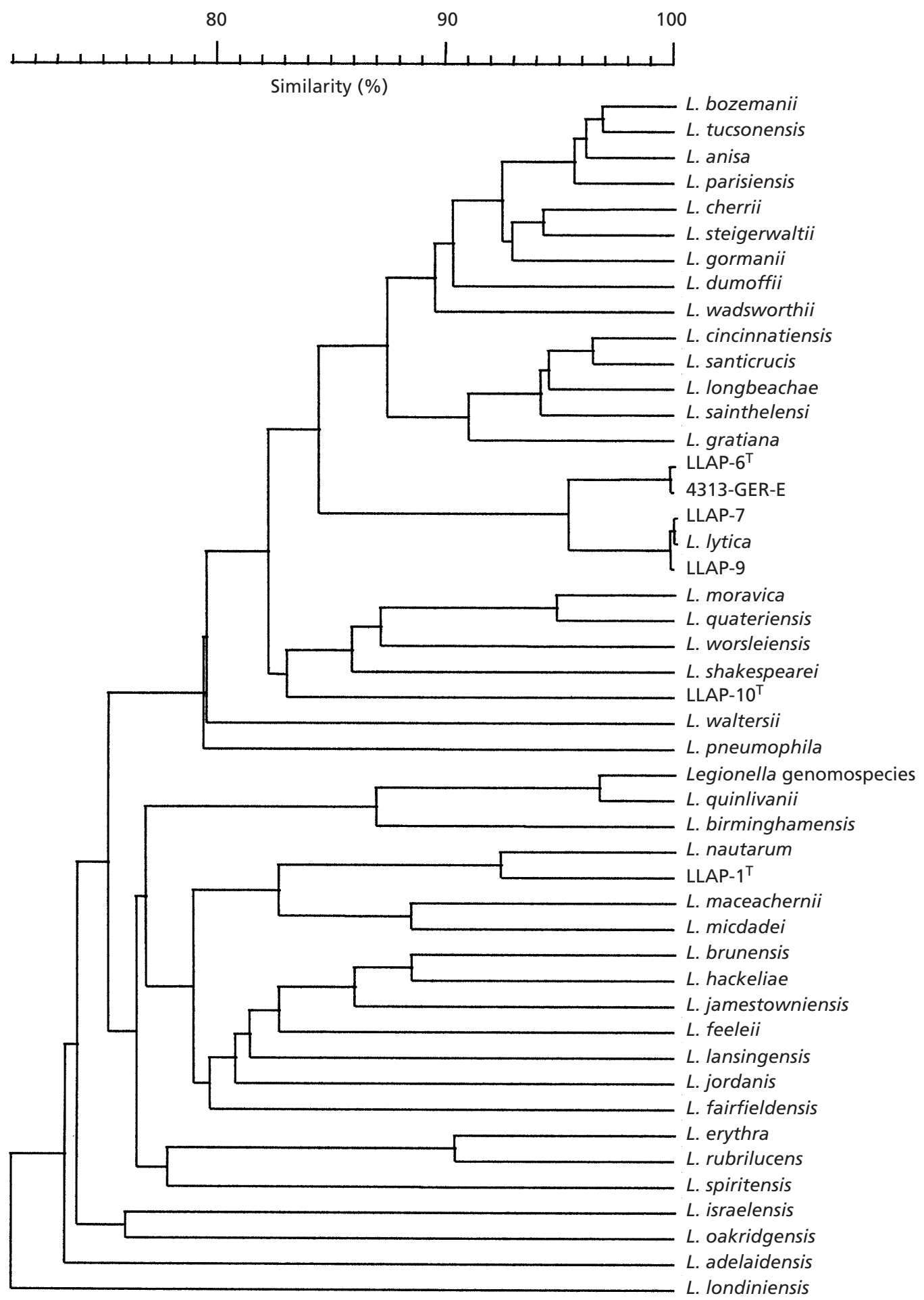

Fig. 1. UPGMA phylogenetic dendrogram of sequence similarities found among Legionella species and LLAP strains. The horizontal bar joining two isolates or clusters indicates the level of similarity.

were compared with those published for the mip gene from other species (Ratcliff et al., 1998). The UPGMA phylogenetic dendrogram of interspecies relatedness is presented in Fig. 1. LLAP- $1^{\mathrm{T}}$ was $92.4 \%$ similar to Legionella nautarum and less than $84 \%$ similar to all other Legionella species. LLAP-6 ${ }^{\mathrm{T}}$ and 4313-GER-E were $99.8 \%$ similar to each other. L. lytica, LLAP-7 and LLAP-9 were clustered together with a similarity of $99.8 \%$. The latter two clades were $95 \%$ related to each other, demonstrating a degree of relatedness, but 
$<85 \%$ similar to all other species. LLAP- $10^{\mathrm{T}}$ was $<86 \%$ similar to any other species.

\section{DNA homology studies}

On the basis of total DNA relatedness as determined by the hydroxyapatite method at $60^{\circ} \mathrm{C}, \mathrm{LLAP}-1^{\mathrm{T}}$ was $62.5 \%$ related to L. nautarum but $<24 \%$ related to all other strains. LLAP-6 ${ }^{\mathrm{T}}$ and 4313-GER-E had a total DNA relatedness of $91 \%$. Similarly, L. lytica, LLAP7NF, LLAP-7FL and LLAP-9 were $92.5 \%$ related. $L$. lytica was $<14 \%$ related to all other strains (Giles et al., 1995), except for LLAP-6 ${ }^{\mathrm{T}}$ to which it was related by $56 \cdot 5 \%$. LLAP $-10^{\mathrm{T}}$ was $<19 \%$ related to all the species tested. The divergence between strains that were related by $>90 \%$ was $<1 \%$.

\section{DISCUSSION}

The family Legionellaceae was originally created for one genus, Legionella (Brenner et al., 1984). Consequently, the characteristics of both the family and the genus are essentially the same. Members of the Legionellaceae and the genus Legionella are Gramnegative, catalase-positive and oxidase-negative or weakly positive (Orrison et al., 1983; Brenner et al., 1985; Verma et al., 1992; Harrison \& Saunders, 1994; Benson et al., 1996). Amongst other significant similarities shared by members of the family is the requirement of L-cysteine for growth on artificial medium and an inability to ferment or oxidize carbohydrates (Brenner et al., 1984; Holt et al., 1994). The LLAP strains tested were presumptively identified as legionellae based on these characteristics.

Furthermore, the grey-blue colour and cut glass appearance seen in early growth of all LLAP colonies is typical of most legionellae. The morphology of legionellae may vary under adverse conditions of growth (Wilkinson, 1988; Paszko-Kolva et al., 1992). Therefore, it is not unusual to find that LLAP strains which were newly adapted to growth on bacteriological media exhibited distinct and unusual morphology after prolonged incubation. The ability of some Legionella species to autofluoresce when exposed to long wavelength UV light $(366 \mathrm{~nm})$ proves useful for differentiating such isolates. For example, L. rubrilucens and Legionella erythra are known to exhibit red autofluorescence while a number of species, including L. bozemanii, Legionella parisiensis and L. anisa (Brenner et al., 1985) are known to exhibit blue-white autofluorescence. Likewise, LLAP-6 ${ }^{\mathrm{T}}$, LLAP-7FL, LLAP-9, L. lytica and 4313-GER-E exhibited bluewhite autofluorescence while LLAP $-1^{\mathrm{T}}$ and LLAP- $10^{\mathrm{T}}$ did not autofluoresce.

Members of the genus Legionella have been found to differ from other Gram-negative bacteria by the presence of relatively large amounts of branched-chain fatty acids and the absence or presence of trace amounts of hydroxy acids (Lambert \& Moss, 1989). Their cell wall usually contains major ubiquinones with ten or more isoprene units in the side chain (Karr et al., 1982). Of the numerous species of bacteria to which they were compared, the overall CFA profiles and quinone contents of the LLAP strains tested were most similar to those of one another and other legionellae. However, comparing the presence of and/or relative amounts of saturated, unsaturated, branched, cyclopropane and hydroxy acids enabled differentiation into four CFA groups. The fatty acid composition of LLAP $-1^{\mathrm{T}}$ differed from those of the other three groups (Table 2) by the presence of i-16:1? $(1-2 \%)$ and larger amounts $(>5 \%)$ of $15: 1 \omega 6 \mathrm{c}$ and the absence of 17:0, i-18:0 and 18:0. LLAP-7NF, LLAP-7FL and LLAP-10 $0^{\mathrm{T}}$ (Group 2 strains) differed from strains of other CFA groups by the presence of larger amounts (4-9\%) of $\mathrm{i}-14: 0$ and the absence of hydroxy acids (except for 0-trace amounts of 3-OH14:0 in L. lytica). LLAP-9 (Group 3) was distinguished from strains of other CFA groups by the presence of $12: 0(2 \%)$ and four hydroxy acids : $3-\mathrm{OH}-10: 0,3-\mathrm{OH}-$ 12:0, 3-OH-14:0 and 2-OH-15:0 (trace-11\%). The CFA compositions of LLAP- $6^{\mathrm{T}}$ and $4313-$ GER-E differed from those of other groups by the presence $(1-5 \%)$ of $\mathrm{i}-3-\mathrm{OH}-15: 0, \mathrm{i}-13: 0$ and $\mathrm{i}-17: 0$ as well as larger amounts $(5-6 \%$ vs trace-1\%) of i-15:0. In summary, all of the strains tested contained large amounts of branched-chain acids and in some cases small to moderate amounts of ester-linked hydroxy acids. The presence of such ester-linked hydroxy acids was useful for the classification and differentiation of Groups 3 and 4. In addition, all of the strains tested contained ubiquinones in which the isoprenoid side chain contained ten or more isoprene units.

Despite varying degrees of cross-reactions, it was clear that LLAP- ${ }^{\mathrm{T}}$, LLAP-6 ${ }^{\mathrm{T}}$, LLAP-9 and LLAP- $10^{\mathrm{T}}$ were distinct in their serological reactions, while LLAP-7NF, LLAP-7FL and L. lytica were similar on the basis of their serological reactions. Further tests may be needed to clarify the serogrouping of these strains.

Based on a DNA reassociation value of $70 \%$ and divergence of less than $5 \%$ at optimum temperature $\left(60{ }^{\circ} \mathrm{C}\right)$ between members of the same species (Priest \& Austin, 1993), DNA reassociation experiments confirmed that LLAP-1 ${ }^{\mathrm{T}}$, LLAP-6 ${ }^{\mathrm{T}}$ and LLAP- $10^{\mathrm{T}}$ represent three new species of Legionella. On the other hand, LLAP-7NF, LLAP-7FL, LLAP-9 and L. lytica belong to the same species. However, LLAP-9 is phenotypically distinct from the other strains of the same species and possibly represents a different serogroup from LLAP-7NF, LLAP-7FL and L. lytica.

Based on the level of mip gene similarity between the currently described species of Legionella (Ratcliff et al., 1998), the level of similarity determined for LLAP$1^{\mathrm{T}}$, LLAP- $6^{\mathrm{T}}$ and LLAP- $10^{\mathrm{T}}$ is consistent with each of the three isolates representing a new species. LLAP- ${ }^{\mathrm{T}}$ showed a degree of relatedness to L. nautarum consistent with the total DNA homology findings. Similarly, LLAP- $6^{\mathrm{T}}$ showed a degree of relatedness to $L$. 
lytica, also consistent with the total DNA homology findings. L. lytica was recognized as a distinct species by this scheme, being less than $14 \%$ related to all other published species. LLAP-7 and LLAP-9 exhibit the same genotype as strains of L. lytica. Strains 4313GER-E and LLAP- $6^{\mathrm{T}}$ had a near identical mip gene sequence, indicative of belonging to the same species, in spite of the increased culturability of 4313-GER-E on bacteriological media. At least one other strain (Strain TE-1) is known to exist which exhibits the same genotype as LLAP-6 ${ }^{\mathrm{T}}$, but was isolated on BCYE medium after extended incubation at $30^{\circ} \mathrm{C}$ in a candle jar (V. Drasar, personal communication). All of these genotyping results parallel the findings and relationships determined from total DNA homology results, indicating that genotyping based on the mip gene continues to effectively discriminate newly characterized species when the percentage DNA homology is low.

The phenetic characteristics of the LLAP strains studied, including their growth and cultural characteristics, biochemical reactions, CFA profiles and serological reactions are in agreement with previous inferences from phylogenetic analyses (Adeleke et al., 1996; Birtles et al., 1996). The degree of 16S rRNA sequence similarity between LLAPs and validly described members of the genus Legionella was found to be consistent with that between the existing members of the genus. As with the phylogenetic dendrogram based on mip gene sequences (Fig. 1), unrooted consensus trees based on 16S rRNA sequence similarities (Adeleke et al., 1996; Birtles et al., 1996), showed that the LLAP strains studied formed a coherent cluster with other Legionella species. Phylogenetic analysis suggested that LLAP- $1^{\mathrm{T}}$ and LLAP$10^{\mathrm{T}}$, which each belonged to separate clades, represented two new species of Legionella and this was confirmed by DNA homology. LLAP-6 ${ }^{\mathrm{T}}$, LLAP-7, LLAP-9 and L. lytica formed another clade that represented at least one new species. The sequence similarities and branching patterns within the clade suggested that LLAP-7, LLAP-9 and L. lytica may represent the same species, while LLAP- $6^{\mathrm{T}}$ may represent a separate species. DNA homology experiments also confirmed these results. On the strength of these phylogenetic findings and other supporting data, it was proposed that LLAPs be included in the Family Legionellaceae and genus Legionella (Adeleke et al., 1996).

\section{Description of Legionella drozanskii sp. nov.}

Legionella drozanskii (dro'zan.ski.i. N.L. gen. n. drozanskii in honour of Wincenty Drozanski, who isolated the first known LLAP strain and pioneered LLAP research).

Gram-negative, catalase-positive and oxidase-negative. The organism requires L-cysteine for growth on BCYE and does not ferment glucose. The organism exists naturally as a parasite of free-living amoebae but can be grown on BCYE. Slightly convex colonies with entire edges are seen after $3-4 \mathrm{~d}$ incubation at $30^{\circ} \mathrm{C}$. No growth is observed at $35^{\circ} \mathrm{C}$. Cultures are initially grey to blue-grey and have a soft/light butterous consistency. With prolonged incubation, colonies appear to become less grey in colour, tending towards white. Colonies do not autofluoresce. Branched-chain CFAs predominate in cell wall. Although it contains ubiquinones with Q-10, Q-11 and Q-14 isoprene units in the polyprenoid side chain, the major ubiquinones are Q-12 and Q-13. The type strain is LLAP- $1^{\mathrm{T}}$ $\left(=\right.$ ATCC $\left.700990^{\mathrm{T}}\right)$.

\section{Description of Legionella rowbothamii sp. nov.}

Legionella rowbothamii (row.bo'tham.i.i. N.L. gen. n. rowbothamii in honour of Timothy Rowbotham, who isolated the majority of known LLAP strains and has contributed significantly to our knowledge of LLAPs).

Gram-negative, catalase-positive, oxidase-negative bacillus that requires L-cysteine for growth on BCYE and does not ferment glucose. Although it can be grown on artificial media, the organism exists naturally as a parasite of free-living amoebae. Although culturable at $35^{\circ} \mathrm{C}$, optimal growth is observed on BCYE after 3-4 d incubation at $30^{\circ} \mathrm{C}$. The colonies are slightly convex with entire edges and are initially grey to blue-grey with a butterous consistency. With prolonged incubation, the colonies acquire a yellow pigmentation and become slippery and adherent. Colonies exhibit blue-white autofluorescence. The cell wall is predominated by branched-chain CFAs and contains minor amounts of i-3-OH-15:0, a branchedchain ester-linked hydroxy acid. The major ubiquinones are Q-12 and Q-13 with smaller amounts of Q-10, Q-11 and Q-14 isoprene units in the polyprenoid side chain. The type strain is LLAP-6 $6^{\mathrm{T}}(=\mathrm{ATCC}$ $700991^{\mathrm{T}}$ ).

\section{Description of Legionella fallonii sp. nov}

Legionella fallonii (fall'o.ni.i. N.L. gen. n. fallonii in honour of the Late Ronald Fallon who contributed immensely to our knowledge of legionellae and was the first to produce Legionella antigen and antiserum in the UK in 1977. He worked on an isolate from a case on the ship from which LLAP- $10^{\mathrm{T}}$ was isolated).

Gram-negative rod that does not ferment glucose. Catalase-positive, weakly oxidase-positive and requires L-cysteine for growth on BCYE. Exists naturally as a parasite of free-living amoebae but can be grown on BCYE. Optimal growth is observed after 3-4 d incubation at $30^{\circ} \mathrm{C}$. The convex colonies with entire edges are initially grey to blue-grey with a butterous consistency. However, with age, the smooth non-fluorescent colonies become beige to brown in colour. The cell wall contains relatively high amounts of branched-chain CFAs and the major ubiquinones are Q-12 and Q-13. It also contains smaller amounts of ubiquinones Q-10, Q-11 and Q-14 isoprene units in the 
polyprenoid side chain. The type strain is LLAP- $10^{\mathrm{T}}$ $\left(=\right.$ ATCC $\left.700992^{\mathrm{T}}\right)$.

\section{REFERENCES}

Adeleke, A. (1998). The taxonomic identity of Legionella-like amoebal pathogens. $\mathrm{PhD}$ thesis, University of London.

Adeleke, A., Pruckler, J., Benson, R., Rowbotham, T., Halablab, M. \& Fields, B. (1996). Legionella-like amoebal pathogens - phylogenetic status and possible role in respiratory disease. Emerg Infect Dis 2, 225-230.

Benson, R. F. \& Fields, B. S. (1998). Classification of the genus Legionella. Semin Respir Infect 13, 90-99.

Benson, R. F., Drozanski, W. J., Rowbotham, T. J., Bialkowska, I., Losos, D., Butler, J. C., Lipman, H. B., Plouffe, J. F. \& Fields, B. S. (1995). Serologic evidence of infection with 9 Legionella-like amoebal pathogens in pneumonia patients. In Proceedings of the 95th Annual General Meeting of the American Society for Microbiology, Washington, DC, USA, Abstract C-200.

Benson, R. F., Thacker, W. L., Daneshvar, M. I. \& Brenner, D. J. (1996). Legionella waltersii sp. nov. and an unnamed Legionella genomospecies isolated from water in Australia. Int $J$ Syst Bacteriol 46, 631-634.

Birtles, R. J., Rowbotham, T. J., Raoult, D. \& Harrison, T. G. (1996). Phylogenetic diversity of intra-amoebal legionellae as revealed by $16 \mathrm{~S}$ rRNA gene sequence comparison. Microbiology $\mathbf{1 4 2}$, 3525-3530.

Brenner, D. J. (1986). Classification of Legionellaceae: current status and remaining questions. Isr J Med Sci 22, 620-632.

Brenner, D. J., Steigerwalt, A. G., Weaver, R. E., McDade, J. E., Feeley, J. C. \& Mandel, M. (1978). Classification of the Legionnaires' disease bacterium: an interim report. Curr Microbiol 1, 71-75.

Brenner, D. J., Feeley, J. C. \& Weaver, R. E. (1984). Family VII. Genus I. Legionella Brenner, Steigerwalt, McDade 1979, $658^{\mathrm{AL}}$. In Bergey's Manual of Systematic Bacteriology, vol. 1, pp. 279-288. Edited by N. R. Krieg \& J. G. Holt. Baltimore: Williams \& Wilkins.

Brenner, D. J., Steigerwalt, A. G., Gorman, G. W. \& 13 other authors. (1985). Ten new Legionella species. Int J Syst Bacteriol 35, 50-59

Drozanski, W. (1956). Fatal bacterial infection in soil amoebae. Acta Microbiol Pol 5, 315-317.

Drozanski, W. (1991). Sarcobium lyticum gen. nov., sp. nov., an obligate intracellular bacterial parasite of small free-living amoebae. Int J Syst Bacteriol 41, 82-87.

Edelstein, P. H. (1981). Improved semi-selective medium for isolation of Legionella pneumophila from contaminated clinical and environmental specimens. J Clin Microbiol 14, 298-303.

Fields, B. S. (1996). The molecular ecology of legionellae. Trends Microbiol 4, 286-290.

Fields, B. S., Barbaree, J. M., Sanden, G. N. \& Morrill, W. E. (1990). Virulence of a Legionella anisa strain associated with Pontiac fever: an evaluation using protozoan, cell culture and guinea pig models. Infect Immun 58, 3139-3142.

Fox, G. E., Wisotzkey, J. D. \& Jurtshuk, P. J. (1992). How close is close; 16S rRNA sequence identity may not guarantee species identity. Int J Syst Bacteriol 42, 166-170.

Fry, N. K., Warwick, S., Saunders, N. A. \& Embley, T. M. (1991). The use of $16 \mathrm{~S}$ ribosomal RNA to investigate the phylogeny of the family Legionellaceae. J Gen Microbiol 137, 1215-1222.

Giles, D. L., Fields, B. S., Newsome, A. L., Drozanski, W. J. (1995).
Cultivation of Sarcobium lyticum on artificial medium. In Proceedings of the 96th Annual General Meeting of the American Society for Microbiology, Washington, DC, USA, Abstract Q447

Harrison, T. G. \& Saunders, N. A. (1994). Taxonomy and typing of legionellae. Rev Med Microbiol 5, 79-90.

Holt, J. G., Krieg, N. R., Sneath, P. H. A., Staley, J. T. \& Williams, S. T. (1994). Bergey's Manual of Determinative Bacteriology. Baltimore: Williams \& Wilkins.

Hookey, J. V. (1995). Typing and taxonomy of the Legionellaceae: an update. PHLS Microbiol Digest 12, 223-226.

Hookey, J. V., Saunders, N. A., Fry, N. K., Birtles, R. J. \& Harrison, T. G. (1996). Phylogeny of Legionellaceae based on smallsubunit ribosomal DNA sequences and proposal of Legionella lytica comb. nov. for Legionella-like amoebal pathogens. Int $J$ Syst Bacteriol 46, 526-531.

Karr, D. E., Bibb, W. F. \& Moss, C. W. (1982). Isoprenoid quinones of the genus Legionella. J Clin Microbiol 15, 1044-1048.

Lambert, M. A. \& Moss, C. W. (1989). Cellular fatty acid compositions and isoprenoid quinone contents of 23 Legionella species. J Clin Microbiol 27, 465-473.

Moss, C. W. \& Guerrant, G. O. (1983). Separation of bacterial ubiquinones using reverse-phase high performance liquid chromatography. J Clin Microbiol 18, 15-17.

Murray, R. G. E., Brenner, D. J., Colwell, R. R., De Vos, P., Goodfellow, M., Grimont, P. A. D., Pfennig, N., Stackebrandt, E. \& Zavarzin, G. A. (1990). Report of the ad hoc committee on approaches to taxonomy within the Proteobacteria. Int J Syst Bacteriol 40, 213-215.

Orrison, L. H., Cherry, W. B., Tyndall, R. L., Fliermans, C. B., Gough, S. B., Lambert, M. A., McDougal, L. K., Bibb, W. F. \& Brenner, D. J. (1983). Legionella oakridgensis: unusual new species isolated from cooling tower water. Appl Environ Microbiol 45, 536-545.

Paszko-Kolva, C., Shahamah, M. \& Colwell, R. R. (1992). Long term survival of Legionella pneumophila serogroup 1 under lownutrient conditions and associated morphological changes. FEMS Microbiol Ecol 102, 45-55.

Priest, F. \& Austin, B. (1993). Modern Bacterial Taxonomy, 2nd edn. London: Chapman \& Hall.

Ratcliff, R. M., Donnellan, S. C., Lanser, J. A., Manning, P. A. \& Heuzenroeder, M. W. (1997). Interspecies sequence differences in the Mip protein from the genus Legionella: implications for function and evolutionary relatedness. Mol Microbiol 25, 1149-1158.

Ratcliff, R. M., Lanser, J. A., Manning, P. A. \& Heuzenroeder, M. W. (1998). Sequence-based classification scheme for the genus Legionella targeting the mip gene. J Clin Microbiol 36, $1560-1567$.

Rowbotham, T. J. (1983). Isolation of Legionella from clinical specimens via amoebae, and the interaction of those and other isolates with amoebae. J Clin Pathol 36, 978-986.

Rowbotham, T. J. (1986). Current views on the relationship between amoebae, legionellae and man. Isr J Med Sci 22, 678-689.

Rowbotham, T. J. (1993). Legionella-like amoebal pathogens. In Legionella-Current Status and Emerging Perspectives. pp. 137-140. Edited by J. M. Barbaree, R. F. Breiman \& A. P. Dufour. Washington, DC: American Society for Microbiology.

Schlecht, S. \& Drozanski, W. (1987). Mass cultivation of an intracellular bacterial parasite (IBP) of small free living amoebae. Syst Appl Microbiol 10, 92-97. 
Thacker, W. L., Plikaytis, B. B. \& Wilkinson, H. W. (1985). Identification of 22 Legionella species and 33 serogroups with the slide agglutination test. J Clin Microbiol 21, 779-782.

Verma, U. K., Brenner, D. J., Thacker, W. L., Benson, R. F., Vesey, G., Kurtz, J., Dennis, P. J., Steigerwalt, A. G., Robinson, J. S. \& Moss, C. W. (1992). Legionella shakespearei sp. nov., isolated from cooling tower water. Int J Syst Bacteriol 42, 404-407.
Weyant, R. S., Moss, C. W., Weaver, R. E., Hollis, D. G., Jordan, J. J., Cook, E. C. \& Daneshvar, M. I. (1996). Identification of Unusual Pathogenic Gram-negative Aerobic and Facultatively Anaerobic Bacteria, 2nd edn. Baltimore: Williams \& Wilkins.

Wilkinson, H. W. (1988). Hospital Laboratory Diagnosis of Legionella Infections, revised edn, 2nd printing. Atlanta, GA: Centers for Disease Control. 